\title{
STAT activation and differential complex formation dictate selectivity of interferon responses
}

\author{
Joanna Wesoly, Zofia Szweykowska-Kulinska and Hans A. R. Bluyssen $\bowtie$ \\ Institute of Molecular Biology and Biotechnology, University of Adam Mickiewicz, Poznań, Poland
}

Received: 27 December, 2006; revised: 06 February, 2007; accepted: 21 February, 2007

available on-line: 09 March, 2007

\begin{abstract}
Interferons (IFNs) induce gene expression by phosphorylating latent transcription factors belonging to the signal transducer and activator of transcription (STAT) family, mediated by janus kinases (Jaks). STAT dimers directly activate genes containing the IFN $\gamma$ activation site (GAS) DNA element, with different STAT proteins displaying slightly different intrinsic DNA binding specificities. The combinatorial association of STATs with the additional DNA binding adaptor protein interferon regulatory factor (IRF) 9 expands the range of enhancer elements that can be targeted by the JAK-STAT pathway to interferon-stimulated response element (ISRE) and IRF response element (IRE). Based on the amino-acid sequence similarity within the IRF family and functional overlap with the STAT family, in this paper we hypothesize that other IRF members could serve as adapter proteins for the STATs during IFN responses to redirect them to subsets of ISRE, GAS and/or IRE-containing IFN-stimulated genes (ISGs). In addition, the fact that STAT2 homodimers are not capable of binding consensus GAS sites leaves the possibility for a novel type of DNAbinding site bound by STAT2 homodimers and potentially other STAT complexes.
\end{abstract}

Keywords: JAK/STAT pathway, IFNs, IRFs, transcription factor complexes, gene regulation

\section{INTRODUCTION}

Interferons (IFNs) were the first identified members of the important superfamily of biological regulatory proteins called cytokines. IFNs were discovered 50 years ago by Isaacs and Lindenmann (1957) as proteins that inhibit virus replication. They are induced in mammalian cells in response to virus infection, secreted in the circulation, and act on yet uninfected cells to activate a global antiviral state. Thus, IFNs are mediators of cellular homeostatic responses to virus infection. It has become apparent, however, that IFNs do much more than inhibiting virus replication. Like many other cytokines, IFNs have pleiotropic effects on many aspects of cell physiology, including cell growth, cell motility, and cell functions. IFNs represent a family of molecules which can be divided into two main sub families: type I IFNs and type II IFN. Type I IFNs can be pro- duced by many cell types (including leukocytes) and induced by many substances, but the amount produced and the IFN subspecies induced can vary per cell type and per inducer. Viruses and synthetic double stranded RNAs are amongst the best inducers. Type II IFN is largely produced by T lymphocytes and natural killer (NK) cells stimulated by foreign antigens or mitogens.

Initiation of the signal transduction pathway occurs when IFNs interact with their cognate receptors (Fig. 1). Receptor occupancy rapidly triggers signaling cascades through the activation of tyrosine kinases, which culminate in the activation (by tyrosine phosphorylation) of cytoplasmic signaling proteins. Once activated, a ligand-specific set of cytosolic proteins transduce the signal to the appropriate DNA target sequences of IFN-stimulated genes (ISGs) in the nucleus. In this way the type I and type II IFNs induce the expression of partially overlapping sets

${ }^{\square}$ Correspondence to: Dr. J.A.R. Bluyssen, Institute of Molecular Biology and Biotechnology, University of Adam Mickiewicz, Poznań, Poland; tel: (48 61) 829 5832; fax: (48 61) 829 2730; e-mail: johannes.bluijssen@amu.edu.pl

Abbreviations: GAS, gamma-activated sequence; IAD, IRF-associated domain; IFN, interferon; IFNAR, IFN $\alpha$ receptor; IFNGR, IFN $\gamma$ receptor; ISG, IFN-stimulated gene; IRE, IRF-regulated element; IRF, IFN-regulated factor; ISRE, IFN-stimulated response element; Jak, janus kinase; STAT, signal transducer and activator of transcription; SH2, src-homology 2. 


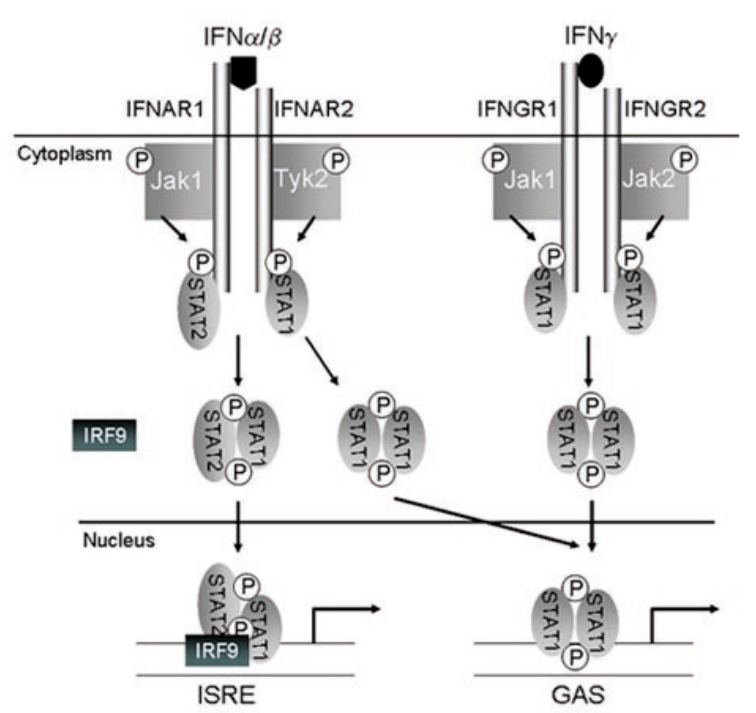

Figure 1. General paradigm of signal transduction and transcriptional activation in cells treated with IFN $\alpha$ and IFN $\gamma$.

Detailed description is given in the text. IFN, interferon; IFNAR, IFN $\alpha$ receptor; IFNGR, IFN $\gamma$ receptor; ISRE, IFN-stimulated response element; GAS, gamma-activated sequence; Jak, janus kinase; STAT, signal transducer and activator of transcription; IRF, IFN-regulated factor; P, phosphorylated tyrosine residue.

of cellular genes. Some of these genes are induced in common by the type I and type II IFNs, whereas others seem to be preferentially induced by one of the IFN types. The similarities and differences in the biological properties of the type I and type II IFNs may be a reflection of the partially overlapping and differential activation of transcription factor complexes and regulation of cellular genes by the two types of IFNs (Darnell et al., 1994; Stark et al., 1998; Levy \& Darnell, 2002; Platanias, 2005).

\section{THE IFN FAMILY OF LIGANDS AND RECEPTORS}

There are many type I IFNs, all of which have considerable structural homology. These include IFN $\alpha$ (which can be further subdivided into 13 different subtypes, IFN $\alpha 1,-\alpha 2,-\alpha 4,-\alpha 5,-\alpha 6,-\alpha 7,-\alpha 8$, $-\alpha 10,-\alpha 13,-\alpha 14,-\alpha 16,-\alpha 17$ and $-\alpha 21), \operatorname{IFN} \beta$, IFNס, $\operatorname{IFN} \varepsilon$, IFN $\kappa$, IFN $\tau$ and IFN $\omega$. IFN $\alpha, \operatorname{IFN} \beta, \operatorname{IFN} \varepsilon$, IFN $\kappa$ and IFN $\omega$ exist in humans, whereas IFNס and IFN $\tau$ have been described only for pigs and cattle, respectively, and do not have human homologues. The genes that encode type I IFNs are clustered on chromosome 9 in humans and on chromosome 4 in mice (Stark et al., 1998; Pestka et al., 2004; Platanias, 2005). The type I IFNs appear to have a common receptor consisting of two subunits, IFNAR-1 and IFNAR-2 (Fig. 1), which are expressed in most tissues
(Novick et al., 1994; Stark et al., 1998; Pestka et al., 2004). Both IFNAR-1 and IFNAR-2 map to chromosome 21 in the human, and chromosome 16 in the mouse. There is a single form of the IFNAR- 1 subunit. However, alternative processing of the IFNAR-2 gene transcript produces long (2c), short (2b), and soluble (2a) forms of the encoded subunit. IFNAR1 knockout mice have not only confirmed the role this receptor subunit plays in mediating the biological response to type I IFNs, but have highlighted the pervasive role these IFNs play in regulating the host response to viral infections and adaptive immunity (Hwang et al., 1995; Le Bon et al., 2001). A limited analysis of IFNAR-2 null mice suggests that this receptor subunit has an important ligand binding activity (Hardy et al., 2001). Other studies, however, have implicated a more important role in signal transduction (Wagner et al., 2002).

By contrast, there is only one type II IFN, IFN $\gamma$ (Stark et al., 1998; Pestka et al., 2004; Platanias, 2005). Its gene is located on chromosome 12 in humans and chromosome 10 in mice, and the protein has no marked structural homology with type I IFNs. IFN $\gamma$ is a markedly different cytokine than the type I IFNs, but it was originally classified in the IFN family because of its ability to 'interfere' with viral infections, which is consistent with the primary definition of IFNs (Isaacs \& Lindenmann, 1957). IFN $\gamma$ plays an important role in the activation of macrophages and lymphocytes through binding to a receptor distinct from that used by type I IFNs. Two kinds of subunits also constitute the IFN $\gamma$ receptor complex (Fig. 1). Genes for the IFN $\gamma$ ligand-binding IFNGR-1 subunit and the accessory IFNGR-2 subunit map to chromosomes 6 and 21 in the human and chromosomes 10 and 16 in the mouse, respectively. Gene targeting studies have also provided important insight into IFN $\gamma$ biology. Mice with disruptions of either IFN $\gamma$ or the IFNGR exhibit profound defects in cellular immunity (Dalton et al., 1993; Huang et al., 1993; Lu et al., 1998). Most notable are deficits in the response to intracellular pathogens (e.g., viruses) and delayed hypersensitivity (DHT) reactions.

\section{IFN-REGULATED GENES}

A group of directly IFN $\alpha / \beta$ regulated genes (ISGs) has been identified in studies using early preparation of recombinant type I IFNs (Friedman et al., 1984; Larner et al., 1984). Characterization of their transcriptional response to IFN $\alpha$ by using in vitro nuclear transcription assays and in vivo promoter analyses has revealed distinctive features of ISG regulation and led to a refinement of the interferon-stimulated response element (ISRE, Fig. 1), with the consensus sequence of AGTTTCNNTTTCC (where $\mathrm{N}$ is any nu- 
cleotide) (Darnell et al., 1994). In general, the ISRE exists in ISG promoters in either orientation, sometimes in multiple copies, and (minor) variations from the consensus sequence have been found in individual ISRE sequences. Functional analysis of a variety of type I IFN-inducible genes (Pellegrini \& Schindler, 1993) has demonstrated that ISRE is necessary for IFN induction.

There are also genes that are known to be activated immediately at the transcriptional level by IFN $\gamma$. In this respect, the study of the guanylate-binding protein $(G B P)$ gene, which is inducible by both $\operatorname{IFN} \gamma$ and IFN $\alpha / \beta$, has led to the identification of the IFN $\gamma$ activation site (GAS, Fig. 1), in addition to an ISRE (Decker et al., 1989; Lew et al., 1989; 1991). In HeLa S3 cells, GBP mRNA accumulated in response to IFN $\alpha$ or IFN $\gamma$. For boths IFNs, the induction was transcriptional and primarily direct. The kinetics of GBP mRNA accumulation in response to types I and II IFN were markedly different, with IFN $\gamma$ producing a slowly-developing and long-lasting transcriptional induction, whereas in IFN $\alpha$-treated HeLa cells the GBP gene was transcribed with an abrupt onset and a rapid decay. A GBP promoter-reporter construct, containing an ISRE sequence, could be activated by IFN $\gamma$ or IFN $\alpha$. Deletion of the ISRE core abolished the response to both IFNs, but interestingly, base substitutions which crippled the ISRE homolog for response to IFN $\alpha$ failed to affect induction by IFN $\gamma$. However, a promoter-proximal element overlapping the ISRE and termed GAS was required for IFN $\gamma$ to utilize the GBP fragment as an inducible enhancer. Subsequently, it has become clear that primary activation of other genes by IFN $\gamma$ operates through a similar GAS-like element (consensus: NTT(C/A)(C/ $\mathrm{T})(\mathrm{C} / \mathrm{T}) \mathrm{N}(\mathrm{T} / \mathrm{G}) \mathrm{AAA})$. Characterization of the IFP 53 promoter (Strehlow et al., 1993) has led to the detection of an IFN $\gamma$ response region containing a GAS but no ISRE, while a 9 nt core region in the $3^{\prime}$ domain of the GRR (IFN $\gamma$ response region) of the Fc $\gamma R I$ gene promoter also resembles the GAS (Pearse et al., 1991; Decker et al., 1997). These results support the conclusion that the GAS site has a more general role in the induction of transcription by IFN $\gamma$, comparable to the ISRE in ISG induction upon IFN $\alpha$ treatment (Fig. 1).

There is considerable overlap between the IFN $\alpha / \beta$ - and IFN $\gamma$-regulated genes. This overlap cannot be explained by the presence of both an ISRE and a GAS. A study of the human $L y-6 A / E$ gene (Khan et al., 1993), which is transcriptionally induced in cells exposed to IFN $\alpha / \beta$ or IFN $\gamma$, indicated that immediate IFN transcriptional response through the GAS element cannot only be used by genes inducible by IFN $\gamma$, but also by genes induced by IFN $\alpha$. Alternatively, in some cases not the GAS element, but the ISRE sequence has been shown to be involved in immediate IFN $\gamma$ transcriptional response (Reid et al., 1989; Ohmori \& Hamilton, 1993; Bluyssen et al., 1995). So, in conclusion it seems possible that under certain conditions, the IFN $\gamma$ pathway can end up in activation of an ISRE, and IFN $\alpha / \beta$ might also be able to activate a GAS element (see below).

\section{IFN $\alpha$ ACTIVATION OF ISGF3}

Using electrophoretic mobility shift assay (EMSA), IFN-stimulated gene factor (ISGF) 3 was the first identified multimeric complex to recognize the ISRE and to serve as a positive regulator in IFN $\alpha$ / $\beta$-mediated induction of cellular genes (Levy et al., 1989; Fu et al., 1990; Kessler et al., 1990). The activity of ISGF3 is apparently produced from pre-existing polypeptides (Levy et al., 1989) and it is formed from two components which have been designated ISGF3 $\alpha$ and ISGF3 $\gamma$. ISGF3 $\alpha$ appeared to be composed of two cytoplasmic polypeptides (p91 and p113). Sequence comparison showed that the p113 and p91 proteins have $42 \%$ sequence identity (Fu et al., 1990; Kessler et al., 1990; Schindler et al., 1992a). Interestingly, these proteins were found to be members of a novel family of signaling proteins, called the STATs (Darnell et al., 1994; Levy \& Darnell, 2002), and named STAT1 (p91) and STAT2 (p113) (Fig. 1). STAT1 and STAT2 represent two of the seven mammalian STATs that range in size from 90 to $115 \mathrm{kDa}$ and contain several conserved functional domains (see below).

The single protein that constituted ISGF3 $\gamma$ was found to be a novel member of the IRF family (see below) and subsequently renamed IRF9 (Veals et al., 1992; Bluyssen et al., 1996) (Fig. 1). IRF9 is active and mostly cytoplasmic in untreated cells, but following IFN $\alpha$ treatment it accumulates in the nucleus (Kessler et al., 1990). Its induction by IFN $\gamma$ could contribute to the synergy between IFN $\alpha$ and IFN $\gamma$ (Levy et al., 1990). IRF9 was identified as a single polypeptide with an apparent molecular mass of $48 \mathrm{kDa}$, therefore also indicated as $\mathrm{p} 48$. It is the $\mathrm{N}$-terminal coiled-coil domain of STAT1 and STAT2 that interact with IRF9 to form ISGF3 (Horvath et al., 1996; Martinez-Moczygemba et al., 1997). The IRF9 protein has a conserved amino-terminal DNA-binding domain and a carboxy-terminal STAT-binding domain. Additional studies determined that IRF9 recognizes a core ISRE sequence and that STAT1 promotes contact with additional flanking nucleotides (Qureshi et al., 1995; Bluyssen \& Levy, 1997). STAT2 does not appear to interact directly with DNA.

Activation of ISGF3 as a nuclear, DNA-binding protein is an early event in IFN $\alpha / \beta$ signaling, being detectable within 2 min following exposure of cells to IFN $\alpha$ (Levy et al., 1989). ISGF3 $\alpha$ proteins, isolated with anti-ISGF3 $\alpha$ protein antibodies from cells treated with IFN $\gamma$ plus IFN $\alpha$, are phosphorylated 
on tyrosine residues (Schindler et al., 1992b). In fact, a single tyrosine, Tyr701 for STAT1 and Tyr690 for STAT2, is phosphorylated (Shuai et al., 1993) and has been shown to be important in ISGF3 activation (Fig. 1). These events trigger the association of STAT1 and STAT2 in an immunoprecipitable complex with IRF9, which translocates to the nucleus (Schindler et al., 1992b) and which has a 20 to 30-fold higher ISRE binding affinity than IRF9 allone (Levy et al., 1989; Kessler et al., 1990). Gene targeting studies in mice have confirmed the critical role of STAT1, STAT2 and IRF9 in mediating the biological responses to type I IFN (Durbin et al., 1996; Kimura et al., 1996; Meraz et al., 1996; Park et al., 2000).

\section{IFN $\gamma$-INDUCED ACTIVATION OF GAF}

An IFN $\gamma$-induced protein factor with affinity for GAS in the promoter of the GBP gene was named $\gamma$-IFN activation factor (GAF). GAF was induced in cytoplasmic extract preparations by IFN $\gamma$ within $15 \mathrm{~min}$, and the kinetics of its activation in cells correlated with the transcriptional activation of GBP (Decker et al., 1991). Thus, GAF may exist in a latent form in the cytoplasm and be rapidly activated following treatment with IFN $\gamma$. Upon activation GAF is translocated to the nucleus and binds GAS. The size of the protein that contacts DNA in the GAF-GAS complex was found to be about $90 \mathrm{kDa}$ (Shuai et al., 1992; Igarashi et al., 1993; Khan et al., 1993; Pearse et al., 1993; Strehlow et al., 1993), a similar size as one of the ISGF3 proteins (STAT1) (Fu et al., 1990; 1992; Schindler et al., 1992a; 1992b). Experiments with specific antibodies directed against STAT1 subsequently showed that STAT1 participates in a GAF gel-shift complex, whereas STAT2 does not. It was suggested that STAT1 alone could be responsible for GAF activity (Shuai et al., 1992) (Fig. 1).

Staurosporine, an inhibitor of protein kinases that blocks the IFN $\alpha$-dependent formation of ISGF3 and the IFN $\alpha$-dependent phosphorylation of STAT1 (Schindler et al., 1992b), prevents also the appearance of the GAF DNA binding activity (Shuai et al., 1992) and blocks the IFN $\gamma$-dependent transcription of the GBP gene in isolated nuclei. It turned out that GAF (STAT1) is converted to a form that binds DNA by IFN $\gamma$-induced phosphorylation on the same tyrosine (Tyr701) as in response to IFN $\alpha / \beta$ (Schindler et al., 1992b; Shuai et al., 1992). This observation was confirmed in experiments by Muller et al. (1993), who showed that complementation of U3A mutants (human fibroblast cell line which lacks STAT1) with cDNA constructs expressing STAT1 completely restored the response to both IFN $\alpha$ and IFN $\gamma$ and the ability to form ISGF3 (Muller et al., 1993). Thus, STAT1 mediates activation of transcription in re- sponse to IFN $\gamma$ (Fig. 1). Studies in STAT1 knock out mice have confirmed the critical role STAT1 plays in mediating the biological response to IFN $\gamma$ (Dalton et al., 1993; Huang et al., 1993; Durbin et al., 1996; Meraz et al., 1996; Lu et al., 1998).

\section{TYROSINE KINASES AND TYROSINE PHOSPHORYLATION INVOLVED IN THE IFN SIGNALING PATHWAYS}

The complementation of a collection of human IFN-resistant mutant cell lines has provided a direct evidence for the involvement of the janus kinase (Jak) family of non-receptor protein tyrosine kinases in the IFN response pathways (Darnell et al., 1994; Stark et al., 1998). This family has four identified members, Jak1-3 and Tyk2 (Darnell et al., 1994; Stark et al., 1998). Each is about $130 \mathrm{kDa}$ in mass and is characterized by the presence of a classical carboxy-terminal protein tyrosine kinase domain, an adjacent kinase or kinase-related domain and five further domains of substantial amino acid similarity extending towards the amino terminus. Of the known Jaks, Jak1, Jak2, and Tyk2 kinases play central roles in mediating IFN-dependent biological responses (Fig. 1), including induction of the antiviral state (Darnell et al., 1994; Stark et al., 1998).

Overlapping subsets of Jaks are involved in signaling by the two types of IFNs. Jak1 and Tyk2 kinases function in type I IFN signaling, and the Jak1 and Jak2 kinases function in type II IFN signaling (Darnell et al., 1994; Stark et al., 1998) (Fig. 1). Tyk2 interacts with the IFNAR-1 receptor subunit, and Jak1 interacts with the IFNAR-2 subunit of the type I IFN receptor. Jak1 also interacts with the IFNGR-1 receptor subunit, and Jak2 interacts with the IFNGR-2 subunit of the type II IFN receptor. Subsequent studies led to the development of a new signaling paradigm, the JAK/STAT pathway. Activation of the JAKs and the general type I and type II IFN signaling paradigm is summarized in Fig. 1 (Darnell et al., 1994; Stark et al., 1998; Platanias, 2005).

Type I IFN signaling is initiated when the ligand binds to its dimeric receptor IFNAR. This promotes a change in receptor conformation, leading to the activation of two receptor-associated Jaks, Jak1 and Tyk2, through a transphosphorylation event. The activated Jaks then phosphorylate conserved tyrosine residues in the cytoplasmic tails of IFNAR. These phosphotyrosyl residues subsequently serve as docking sites for the recruitment of src-homology 2 (SH2)containg signaling molecules like STAT1 and STAT2. Once at the receptor, the STAT proteins themselves become Jak substrates. STAT1 and STAT2 are each phosphorylated on a single tyrosine (Y701 for STAT1 and Y690 for STAT2), whereupon they are released 
from the receptor and dimerize. The dimerization involves interaction between the phosphorylated tyrosine of one STAT molecule and the SH2 domain of the dimer partner. These dimers subsequently move to the nucleus, where they associate with IRF9 to form a stable ternary complex on the ISRE, culminating in the transient induction of target genes. Evidence exists that under certain conditions type I IFNs are able to activate genes through a second STAT-based signaling cascade entailing the formation of STAT1 homodimers, which then promote the expression of a distinct set of GAS-driven genes. This second pathway is primarily activated by IFN $\gamma$ (see below) and is likely to account for some of the functional overlap between type I and type II IFNs.

The important realization that IFN $\gamma$ transmits signals through the formation of STAT1 homodimers and the demonstration that the two IFN $\gamma$ receptor chains (IFNGR-1 and -2) associate with Jak1 and Jak2, have led to the development of a distinct and simpler IFN $\gamma$ signaling paradigm. The signal transduction pathway initiated by binding of IFN $\gamma$ to its receptor first leads to intracellular activation of Jak1 and Jak2, through transphosphorylation. The Jaks then phosphorylate the IFN $\gamma$ receptor at specific tyrosine residues which serve as docking sites for the transcription factor STAT1. Upon activation by phosphorylation through the Jaks, STAT1 homodimerizes and translocates into the nucleus to activate a distinct set of genes containing the GAS DNA element. Together, the IFN-inducible STAT1 and STAT2 proteins thus permit a direct transmission of signals from the cell surface to the nucleus at GAS or ISREdependent genes, resulting in the generation of partially overlapping type I and type II IFN-mediated responses.

\section{ADDITIONALLY DISCOVERED PATHWAYS IN TYPE I AND TYPE II IFN SIGNALING}

It becomes more and more clear that other types of STAT complexes can be formed in response to IFNs, which provides an additional twist to the general signaling paradigm of type I and type II IFNs (Fig. 2). Type I IFN stimulates tyrosine phosphorylation of both STAT1 and STAT2. STAT1-STAT2 heterodimers, in combination with IRF9, interact with ISRE sequences to activate gene expression, while STAT1 homodimers interact with GAS sequences. However, type I IFN-inducible STAT1-STAT2 heterodimers can also bind a GAS-like element in the absence of IRF9 (Ghislain \& Fish, 1996; Li et al., 1996; Ghislain et al., 2001; Brierley \& Fish, 2005; Brierley et al., 2006). Within this complex, both STAT1 and STAT2 contribute to GAS binding. Indeed, cells expressing a STAT2 protein with V453I, V454I (VV-II)

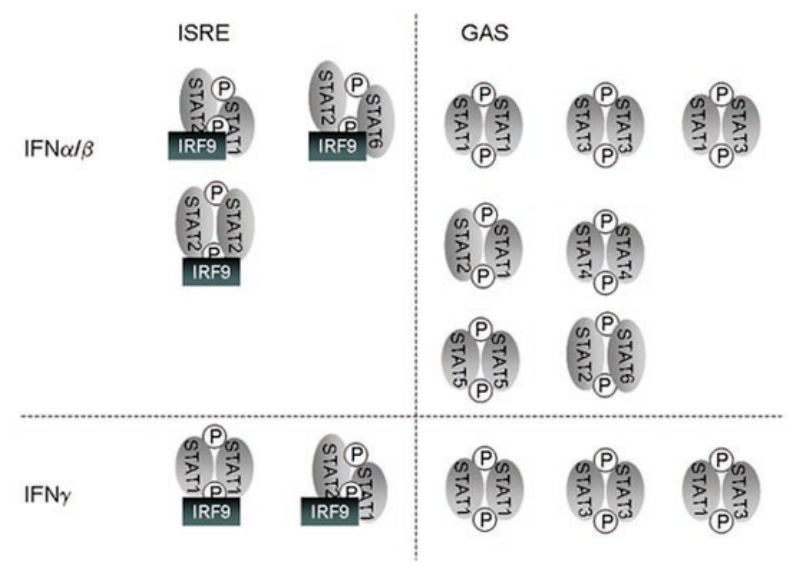

Figure 2. Additionally identified STAT transcription factor complexes formed in response to type I and type II IFNs.

Detailed description is given in the text. IFN, interferon; ISRE, IFN-stimulated response element; GAS, gamma-activated sequence; STAT, signal transducer and activator of transcription; IRF, IFN-regulated factor; P, phosphorylated tyrosine residue.

mutations within its DNA-binding domain are significantly less responsive to the antiviral and growth inhibitory effects of IFN. These cells also exhibit diminished IFN-inducible GAS-driven transcriptional activation and gene expression. This VV-II STAT2 mutant reduces the DNA-binding activity of STAT2containing heterodimers to GAS elements. Taken together, these data demonstrate that IFN-inducible (ISGF3-independent) STAT1-STAT2 heterodimers contribute to the biological responses to type I IFNs (Brierley \& Fish, 2005).

Although IFN $\gamma$ predominantly activates STAT1 homodimers, other STAT1-containing complexes have also been identified (Fig. 2). In murine primary embryonic fibroblasts, IFN $\gamma$-induced STAT1 and STAT2 tyrosine phosphorylation and ISGF3 formation leading to expression of ISRE-containing genes (Matsumoto et al., 1999; Zimmermann et al., 2005). In addition, this could implicate that IFN $\gamma$ may also induce the formation of STAT1-STAT2 heterodimers directly binding to GAS elements. Moreover, evidence exists that STAT1 homodimers in the presence of IRF9 can also bind the ISRE, allowing ISRE-containing genes to respond to IFN $\gamma$ in the absence of phosphorylated STAT2 (Bluyssen et al., 1995; 1996). The STAT1/IRF9 complex displays a lower affinity for the ISRE than does classical ISGF3. IFN $\gamma$ induced activation of this complex, preferentially formed at high concentrations of IRF9 and STAT1, may explain some of the overlapping responses of ISRE-containing genes to type I and type II IFNs (Bluyssen et al., 1995; 1996; Kimura et al., 1996; Majumder et al., 1998; Matsumoto et al., 1999; Decker et al., 2005; Takaoka \& Yanai, 2006). Together, the four 
distinct multimeric complexes activated by type I and type II IFNs (ISGF3, GAF, STAT1:STAT2 and STAT1-IRF9) contribute to the characteristic patterns of gene transcription induced by these cytokines.

\section{STAT2 HOMODIMERS}

STAT2, like STAT1, is also capable of forming stable homodimers when phosphorylated in response to IFNa (Bluyssen \& Levy, 1997). These STAT2 homodimers were shown to interact with IRF9 and activate transcription of ISRE-containing genes in response to type I IFN (Bluyssen \& Levy, 1997) (Fig. 2). However, this complex is less stable on DNA and therefore a less potent transcription complex compared to ISGF3. The increased affinity of ISGF3 over STAT2-IRF9 appears to be caused by additional DNA contacts contributed by STAT1 adjacent to the primary IRF9-binding sequence. STAT2, in contrast, is incapable of directly contacting the ISRE sequence. The biological significance of the STAT2-IRF9 complex is difficult to assess. Although this transcription complex is capable of being formed in response to IFN $\alpha$, its low DNA binding affinity for an ISRE sequence precludes transcriptional responses at modest protein concentrations. Thus, U3A cells that lack STAT1 but express STAT2 do not detectably express ISRE-containing genes (Muller et al., 1993). Similarly, mouse strains lacking STAT1 are also impaired in transcription of IFN $\alpha$-stimulated genes (Durbin et al., 1996; Meraz et al., 1996). However, in both U3A cells and in STAT1 knock out mice, constitutive levels of IRF9 are reduced relative to wild type and neither IRF9 nor STAT2 levels can be induced in response to IFN treatment. Therefore, active STAT2-IRF9 complexes would not be expected to be detected. It remains possible that natural situations of abundant STAT2 and IRF9 exist where STAT2-IRF9 complexes could mediate a weak transcriptional response to IFN $\alpha$. It also remains possible that alternative DNA sequences or alternative adaptor proteins exist which allow STAT2 homodimers to be recruited to DNA and activate transcription without the direct participation of STAT1. Recently, several articles were published in which a possible biological role in viral infection was proposed for this complex. For example, Hahm and coworkers (2005) showed that viruses evade the immune system through a type I IFN-mediated STAT2-dependent, but STAT1-independent, mechanism. Another study showed STAT2 dependency, but not STAT1, of IRF7 expression during viral infection (Ousman et al., 2005). In contrast, IRF9 expression in response to IFN $\alpha$ required both STAT1 and STAT2. A third study describes the mechanism of IFN regulation of the antiviral protein A3G. Notably, IFNa induction of A3G was STAT1 independent, but STAT2 dependent in mouse liver cells. However, STAT1 signaling was functional and required for IFN $\gamma$-induction of A3G in the cells (Sarkis et al., 2006). As was suggested by the authors, a potential mechanism responsible for IFNa induction of A3G could involve STAT2-IRF9-containing complexes.

Although STAT2 forms homodimers in response to IFNa (Bluyssen \& Levy, 1997) and its DNA binding domain is highly conserved among the STATs and necessary for full transcriptional activity of STAT1-STAT2 heterodimers (Brierley \& Fish, 2005; Brierley et al., 2006), untill now no GAS-related DNA sequences have been detected that bind STAT2 homodimers (H.A.R. Bluyssen and D.E. Levy, unpublished results). Recently, subsets of GAS-dependent ISGs were identified whose activation was exclusively regulated by ISGF3-independent STAT2-containing complexes (Brierley et al., 2006), possibly including STAT2 homodimers. In addition, using chromatin immunoprecipitation and DNA microarray analysis, Hartman et al. (2005) identified regions on chromosome 22 bound by STAT1 and STAT2 in IFN-treated cells. Notably, the IFN $\alpha$ induction revealed nonconserved STAT1 occupancy at GAS sites as well as novel sites of STAT1 binding not evident in IFN $\gamma$ treated cells. Many of these correlated with binding by STAT2, but others were STAT2-independent. In addition, novel sites of STAT2 binding were identified independent of STAT1, suggesting that multiple mechanisms direct STAT1 and STAT2 to their targets under different activation conditions. These novel STAT2-binding sites could include GAS elements. On the other hand, it is entirely possible that STAT2 homodimers are capable of binding to a DNA sequence distinct from either the ISRE or the GAS elements. The distinct multimeric complexes activated by type I and type II IFNs that have been detected on ISRE or GAS elements are depicted in Fig. 2.

\section{OTHER STAT FAMILY MEMBERS INVOLVED IN IFN RESPONSES}

In addition to STAT1 and STAT2, five other members of the STAT family have been identified (Fig. 3), which are between 750 and 850 amino acids long and share well-defined structurally and functionally conserved domains (Levy \& Darnell, 2002): an N-terminal domain involved in formation of multiple dimer complexes and methylation, a coiledcoil region (consisting of four $\alpha$-helices, as deduced from the crystal structures of STAT1 and STAT3) for interactions with other transcription factor partners and chaperone proteins (Sehgal, 2003), a highlyconserved DNA-binding domain which possesses an immunoglobulin-type fold (residues 318-488), a conserved SH2 domain (residues 577-683) that in- 


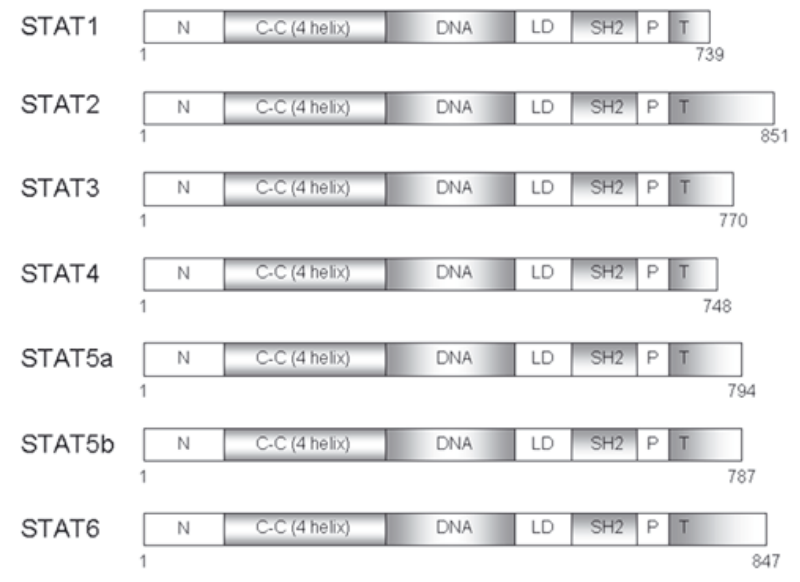

Figure 3. Schematic representation of STAT protein family and their conserved functional domains.

Detailed description is given in the text. N, N-terminal domain; C-C, coiled-coil; DNA, DNA-binding domain; LD, linker domain; SH2, src-homology 2 domain; $\mathrm{P}$, phosphorylated tail segment; T, trans activation domain.

teracts with phosphorylated tyrosine motifs for specific contacts between STATs and receptors and for STAT dimerization, and an $\alpha$-helical linker domain (residues 488-576) that bridges the DNA-binding and $\mathrm{SH} 2$ domains. Adjacently, a conserved tyrosine residue is present that becomes phoshorylated upon activation of the STAT at the receptor-kinase complex. The carboxy-terminal part of STATs is the least conserved domain and was determined to be an important transcription activation domain.

The IFN $\gamma$ signaling model in which STAT1 homodimerizes, translocates into the nucleus and binds to members of the GAS family of enhancers (see Fig. 1), is now an accepted paradigm that explains an important mechanism of how receptors for many cytokines are coupled to their specific STAT signaling systems (Levy \& Darnell, 2002). STAT1, 2, $3,4,5 \mathrm{~A}, 5 \mathrm{~B}$ and 6 all form homodimers. STAT1 and STAT2, STAT1 and STAT3, STAT5a and STAT5b and STAT2 and STAT6 can also form heterodimers, depending on the nature and concentration of the activating ligand. The GAS element is palindromic and the sequence $\operatorname{TTCN}_{(2-4)}$ GAA defines the optimal binding site for all STATs, with the exception of STAT2 which appears to be defective in GAS-DNA binding (see above). This consensus sequence provides an opportunity for most STAT homodimers to exhibit unique DNA binding preferences. In part this is determined by the spacing between the palindromic half sites. Thus, STAT1 binds to an element with canonical $\mathrm{N}=3$ spacing, while STAT3 and STAT6 favor elements with $\mathrm{N}=2$ and $\mathrm{N}=4$, respectively (Horvath et al., 1995; Seidel et al., 1995). Additionally, STATs are able to bind cooperatively to tandem GAS elements (6-10 bp apart), further contributing to DNA binding specificity (Vinkemeier et al., 1996; Xu et al., 1996).
Although STAT1 and STAT2 are the most important mediators of responses to type I IFNs, also other STATs have been found to be activated by this type of IFN (Fig. 2). For example, STAT3 and STAT5 are phosphorylated by different type I IFNs in many cell types, involving Tyk2 and Jak1 and leading to the formation of different hetero- and homodimers (Kisseleva et al., 2002; Takaoka \& Yanai, 2006). STAT4 and STAT6 can also be activated by IFN $\alpha$, but such activation seems to be restricted to certain cell types, such as endothelial cells or cells of lymphoid origin. In mature B cells, for example, IFN $\alpha$ also induces tyrosine phosphorylation of STAT6, leading to the formation of a STAT2-STAT6 heterodimer as well as an ISGF3-like complex comprising STAT2, STAT6, and IRF9 (Gupta et al., 1999). However, the contribution of these additional complexes to type I IFN signaling has yet to be determined. As mentioned above, IFN $\gamma$ mainly activates STAT1. However, under certain conditions STAT3 can also be activated by IFN $\gamma$ (Qing \& Stark, 2004; Ramana et al., 2005) (H.A.R. Bluyssen, unpublished results) (Fig. 2). In this respect, it is of interest that STAT1 and STAT3 have opposing biological effects: STAT3 stimulates growth, and STAT1 is a growth inhibitor. The activation of these two transcription factors in response to IFN $\gamma$ suggests that their relative abundance, which may vary substantially in different cell types, under different conditions is likely to have a major impact on how cells behave in response to type II IFN (Levy \& Lee, 2002; Qing \& Stark, 2004; Ramana et al., 2005).

\section{OTHER IRF FAMILY MEMBERS INVOLVED IN IFN RESPONSES}

IRFs are a family of transcription factors with diverse functions that include host defense, cell cycle regulation, apoptosis, oncogenesis and immune cell development (Taniguchi et al., 2001; Barnes et al., 2002). Currently there are nine members of the mammalian IRF family (IRFs 1 to 9), all of which contain a conserved DNA binding domain. IRF4 was formerly known as PIP, IRF8 as ICSBP and IRF9 as p48/ISGF3 $\gamma$ (Bluyssen et al., 1996). The DNA binding domain is located at the amino termini of IRFs and consists of a five-tryptophan repeat that binds to a specific GAAA genomic sequence (IRF element: IRE), found not only within the promoters of IFN $\alpha$ and IFN $\beta$ genes, but also in ISGs (ISRE core). The IRE is similar to but shorter than the ISRE and is not recognized by ISGF3. The IRFs become activated via phophorylation at their carboxyl terminus, after which they translocate to the nucleus to effect transcription of IRE- and ISRE-containing genes. The carboxy-terminal regions of IRFs, except IRF1 and IRF2, have an IRF associa- 
tion domain (IAD) that is responsible for homo- and heteromeric interactions with other family members or transcription factors such as PU.1 and STAT (Taniguchi et al., 2001).

The various IRFs differ in cellular localization, structural properties and activation-induced stimuli, thus conferring each IRF with unique functions. Their role as vital components of the host defense against viral and bacterial infections is well established (Honda \& Taniguchi, 2006). Among the IRFs, IRF1, IRF2, IRF3, IRF5, and IRF7 have been implicated as regulators of type I IFN gene transcription (Fig. 4). For example, IRF1 and IRF2 were identified in studies of the transcriptional regulation of the human IFN $\beta$ gene. Overexpression experiments have shown that IRF1 functions as an activator on type I IFN genes and ISGs, whereas IRF2 represses the effect of IRF1 (Taniguchi et al., 2001). Recently, IRF5 has been identified to play an integral role in the Toll-like receptor-mediated regulation of inflammatory cytokine genes, such as interleukin (IL)-12 and TNF- $\alpha$ (Takaoka et al., 2005). Its precise role in type I IFN induction remains unclear. Interestingly, a well-characterized collaboration exists between IRF3, IRF7 and IRF9 that serves to amplify the antiviral response. Specifically, during viral infection, IRF3 has an early role in inducing transcription of IFN $\alpha 4$ and IFN $\beta$ that can subsequently induce IRF7 expression, which is dependent on IRF9 and ISGF3 (Honda et al., 2005). The newly synthesized IRF7 then promotes transcription of different IFN $\alpha$ subspecies, thereby creating a positive feedback mechanism of auto secretion that augments the host antiviral response.

Previous studies have shown that many IRF genes are induced by IFNs (Fig. 4). For example, IRF2, $-3,-5$ and -7 are induced by IFN $\alpha / \beta$ and/or viral infection, whereas IRF8 is IFN $\gamma$-inducible. IRF1 and IRF9 are induced by both type I and type II IFNs

\begin{tabular}{|c|c|c|c|c|c|}
\hline & & \multicolumn{4}{|c|}{ Transcriptional regulation of } \\
\hline & & \multirow[t]{2}{*}{ IF $N \alpha / \beta$ genes } & \multicolumn{3}{|c|}{ ISGs } \\
\hline & & & IRE & ISRE & EIRE \\
\hline \multirow{3}{*}{ 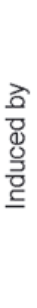 } & $\mathrm{IFN} \alpha / \beta$ & $\begin{array}{l}\text { IRF1, IRF2 } \\
\text { IRF3, IRF7 }\end{array}$ & \multicolumn{2}{|c|}{$\begin{array}{l}\text { IRF1, IRF2 } \\
\text { IRF3, IRF7 } \\
\text { IRF8, IRF9 }\end{array}$} & $\begin{array}{l}\text { IRF4 } \\
\text { IRF8 }\end{array}$ \\
\hline & $\begin{array}{l}\text { Viral } \\
\text { infection }\end{array}$ & $\begin{array}{l}\text { IRF1, IRF2 } \\
\text { IRF3 }\end{array}$ & \multicolumn{2}{|c|}{$\begin{array}{l}\text { IRF1, IRF2 } \\
\text { IRF3, IRF9 }\end{array}$} & \\
\hline & $\mathrm{IFN} \gamma$ & - & \multicolumn{2}{|c|}{ IRF1, IRF9 } & IRF8 \\
\hline
\end{tabular}

Figure 4. Members of the IRF family and their role in transcriptional regulation of IFN $\alpha / \beta$ genes and ISGs. Detailed description is given in the text. IFN, interferon; IRF, IFN-regulated factor; ISRE, IFN-stimulated response element; IRE, IRF element; EIRE, Ets/IRF-response element. and viral infection (Taniguchi et al., 2001; Barnes et al., 2002). Several IRFs have also been shown to serve as regulators of ISG regulation in response to different types of IFNs (Fig. 4). Analyzing mouse embryonic fibroblasts lacking IRF1, IRF9 or both revealed subsets of ISGs depending on IRF1, IRF9 or both for their proper expression (Kimura et al., 1996). As described above, IRF9 associates with STATs and redirects them to ISRE sequences in ISGs. In contrast, IRF1 can regulate expression of ISGs by directly binding the IRE or ISRE on its own or by dimerizing with other IRF members (IRF3, IRF7 or IRF8) (Xie et al., 2001; Xiong et al., 2003). Cooperation between STAT1 and IRF1 in the IFN $\gamma$-regulation of a selective subset of ISGs, containing both a GAS and ISRE site, has also been described (Kumatori et al., 2002). IRF3 and IRF7, together or independently, have also been shown to mediate ISG expression (Nakaya et al., 2001; Grandvaux et al., 2002; Peters et al., 2002; Servant et al., 2002; Yang et al., 2003). Recently a new subtype of IFN-stimulated response element, designated ETS/IRF response element (EIRE), was described that is bound by IRF4 and IRF8 (Fig. 4) in combination with the immune cell specific transcription factor PU.1 (Meraro et al., 2002). This element could lay the molecular basis for the unique regulation of ISGs harboring EIRE (including ISG15 and ISG54), in immune cells. The fact that IRF8 is an IFN $\gamma$-inducible factor could explain why some of the EIREs are also induced by type II IFN. The carboxy-terminal region of IRF9 has been shown to comprise a protein-protein interaction domain necessary for association with STAT proteins during IFN responses (Veals et al., 1993). Most other IRFs contain an analogous IAD, which is important for interaction with other family members or transcription factors. However, it is not clear if apart from IRF9, any of the other IAD-containing IRF members can functionally interact with the STATs. Because of the structural similarity between IRF9 and other IRF members and the functional overlap of the IRFs with the STAT proteins, it is tempting to speculate that in addition to IRF9, other IRFs form multimeric complexes with STATs during IFN responses to redirect them to subsets of ISGs.

\section{CONCLUSION}

Transcription factors acting as dimers and their activity being dependent on a partner is a common paradigm in eukaryotic gene expression regulation. STAT proteins are good examples of this universal rule. The signal transduction pathways activated by the type I and type II IFNs comprise phosphorylation of STAT proteins by IFN receptorassociated Jak kinases, which provides a rapid and specific mechanism for transducing extracellular sig- 


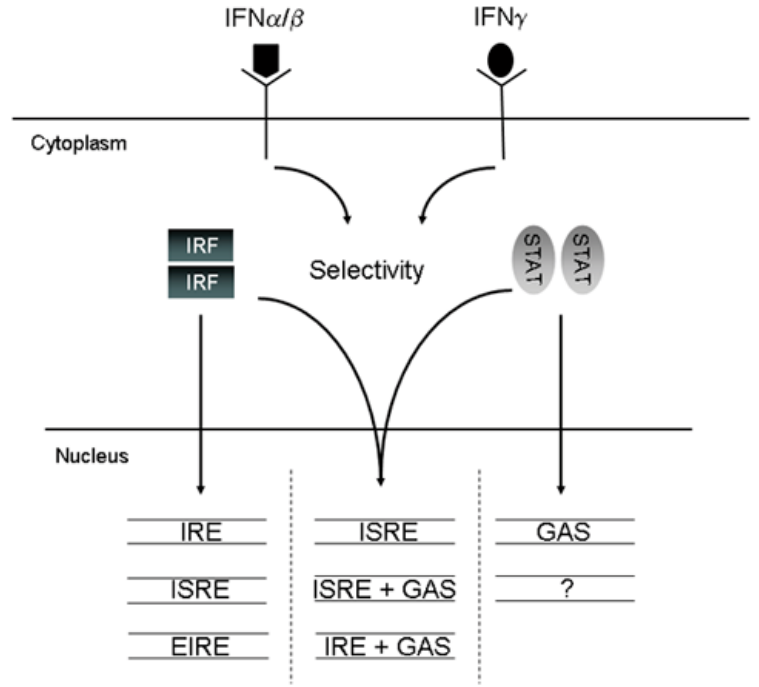

Figure 5. Known and hypothetical convergence of STATs and IRFs in signal transduction and transcriptional activation in cells treated with IFN $\alpha$ and IFN $\gamma$.

Detailed description is given in the text. IFN, interferon; ISRE, IFN-stimulated response element; GAS, gamma-activated sequence; STAT, signal transducer and activator of transcription; IRF, IFN-regulated factor; IRE, IRF element; EIRE, Ets/IRF-response element; ?, unrelated sequence

nals to the nucleus to stimulate the action of ISGs. A simple model, in which type I IFN activates ISGF3 to regulate ISRE-containing genes and type II IFN targets GAS sites via GAF (Fig. 1), has evolved over the years into a more complex model that uses different multimeric transcription factor complexes of STATs and IRF9 activated by both type I and type II IFNs (see Fig. 2). We would like to add another level of complexity to this model, as depicted in Fig. 5. As indicated in the right panel, STAT dimers (homo or hetero) directly bind to GAS sites. Different STAT proteins display slightly different intrinsic DNA binding specificities. The fact that STAT2 homodimers are not capable of binding consensus GAS sites, leaves the possibility for a novel type of DNA-binding site bound by STAT2 homodimers and possibly other STAT complexes (indicated as ? in Fig. 5). The combinatorial association of STATs with the additional DNA binding adaptor protein IRF9 expands the range of enhancer elements that can be targeted by the JAK-STAT pathway to ISRE and IRE. IRF dimers (homo or hetero) directly bind to IRE, EIRE and ISRE sites (left panel of Fig. 5). Based on the amino-acid sequence similarity within the IRF family and the functional overlap with the STAT family, we hypothesize that other IRF members could also serve as adapter proteins for the STATs during IFN responses to redirect them to subsets of ISRE, GAS and/or IRE-containing ISGs and expand the levels of specificity.
Together, these complexes may potentially be responsible for the partially overlapping and differential regulation of cellular genes by type I and type II IFNs. The type of complex formed and the overall role in gene expression in response to either type of IFN may depend on the presence of different STAT proteins and duration of their phosphorylation as well as on the presence and accumulation of DNAbinding adaptor proteins. In addition, differential responses could involve difference in affinity of the different transcription factor complexes towards target DNA sequences and relative affinities of distinct ISRE, IRE, GAS or unrelated sequences. With respect to the functional overlap between IRFs and STATs, it will be of interest to determine if in addition to IRF9, other IRFs form multimeric complexes with STATs during IFN responses to redirect them to subsets of ISRE, GAS and/or IRE-containing ISGs.

\section{Acknowledgments}

This publication was supported by Cordis FP6, Marie Curie Transfer of Knowledge project: MTKDCT-2004-517068; KBN: 91/6.PRUE/2005/2007.

\section{REFERENCES}

Barnes B, Lubyova B, Pitha PM (2002) On the role of IRF in host defense. J Interferon Cytokine Res 22: 59-71.

Bluyssen HA, Levy DE (1997) Stat2 is a transcriptional activator that requires sequence-specific contacts provided by stat 1 and p48 for stable interaction with DNA. J Biol Chem 272: 4600-4605.

Bluyssen HA, Muzaffar R, Vlieststra RJ, van der Made AC, Leung S, Stark GR, Kerr IM, Trapman J, Levy DE (1995) Combinatorial association and abundance of components of interferon-stimulated gene factor 3 dictate the selectivity of interferon responses. Proc Natl Acad Sci USA 92: 5645-5649.

Bluyssen AR, Durbin JE, Levy DE (1996) ISGF3 gamma p48, a specificity switch for interferon activated transcription factors. Cytokine Growth Factor Rev 7: 11-17.

Brierley MM, Fish EN (2005) Functional relevance of the conserved DNA-binding domain of STAT2. J Biol Chem 280: 13029-13036.

Brierley MM, Marchington KL, Jurisica I, Fish EN (2006) Identification of GAS-dependent interferon-sensitive target genes whose transcription is STAT2-dependent but ISGF3-independent. FEBS J 273: 1569-1581.

Dalton DK, Pitts-Meek S, Keshav S, Figari IS, Bradley A, Stewart TA (1993) Multiple defects of immune cell function in mice with disrupted interferon-gamma genes. Science 259: 1739-1742.

Darnell JE Jr, Kerr IM, Stark GR (1994) Jak-STAT pathways and transcriptional activation in response to IFNs and other extracellular signaling proteins. Science 264: 14151421.

Decker T, Lew DJ, Cheng YS, Levy DE, Darnell JE Jr (1989) Interactions of alpha- and gamma-interferon in the transcriptional regulation of the gene encoding a guanylate-binding protein. EMBO J 8: 2009-2014. 
Decker T, Lew DJ, Mirkovitch J, Darnell JE, Jr. (1991) Cytoplasmic activation of GAF, an IFN-gamma-regulated DNA-binding factor. EMBO J 10: 927-932.

Decker T, Kovarik P, Meinke A (1997) GAS elements: a few nucleotides with a major impact on cytokine-induced gene expression. J Interferon Cytokine Res 17: 121-134.

Decker T, Muller M, Stockinger S (2005) The yin and yang of type I interferon activity in bacterial infection. Nat Rev Immunol 5: 675-687.

Durbin JE, Hackenmiller R, Simon MC, Levy DE (1996) Targeted disruption of the mouse Stat1 gene results in compromised innate immunity to viral disease. Cell 84: 443-450.

Friedman RL, Manly SP, McMahon M, Kerr IM, Stark GR (1984) Transcriptional and posttranscriptional regulation of interferon-induced gene expression in human cells. Cell 38: 745-755.

Fu XY, Kessler DS, Veals SA, Levy DE, Darnell JE Jr (1990) ISGF3, the transcriptional activator induced by interferon alpha, consists of multiple interacting polypeptide chains. Proc Natl Acad Sci USA 87: 8555-8559.

Fu XY, Schindler C, Improta T, Aebersold R, Darnell JE Jr (1992) The proteins of ISGF-3, the interferon alphainduced transcriptional activator, define a gene family involved in signal transduction. Proc Natl Acad Sci USA 89: 7840-7843.

Ghislain JJ, Fish EN (1996) Application of genomic DNA affinity chromatography identifies multiple interferon-alpha-regulated Stat2 complexes. J Biol Chem 271: 12408-12413.

Ghislain JJ, Wong T, Nguyen M, Fish EN (2001) The interferon-inducible Stat2:Stat1 heterodimer preferentially binds in vitro to a consensus element found in the promoters of a subset of interferon-stimulated genes. $J$ Interferon Cytokine Res 21: 379-388.

Grandvaux N, Servant MJ, tenOever B, Sen GC, Balachandran S, Barber GN, Lin R, Hiscott J (2002) Transcriptional profiling of interferon regulatory factor 3 target genes: direct involvement in the regulation of interferon-stimulated genes. J Virol 76: 5532-5539.

Gupta S, Jiang M, Pernis AB (1999) IFN-alpha activates Stat6 and leads to the formation of Stat2:Stat6 complexes in B cells. J Immunol 163: 3834-3841.

Hardy MP, Owczarek CM, Trajanovska S, Liu X, Kola I, Hertzog PJ (2001) The soluble murine type I interferon receptor Ifnar-2 is present in serum, is independently regulated, and has both agonistic and antagonistic properties. Blood 97: 473-482.

Honda K, Taniguchi T (2006) IRFs: master regulators of signalling by Toll-like receptors and cytosolic patternrecognition receptors. Nat Rev Immunol 6: 644-658.

Honda K, Yanai H, Negishi H, Asagiri M, Sato M, Mizutani T, Shimada N, Ohba Y, Takaoka A, Yoshida N, Taniguchi T (2005) IRF-7 is the master regulator of type-I interferon-dependent immune responses. Nature 434: 772-777.

Horvath CM, Wen Z, Darnell JE Jr (1995) A STAT protein domain that determines DNA sequence recognition suggests a novel DNA-binding domain. Genes Dev 9: 984-994.

Horvath CM, Stark GR, Kerr IM, Darnell JE Jr (1996) Interactions between STAT and non-STAT proteins in the interferon-stimulated gene factor 3 transcription complex. Mol Cell Biol 16: 6957-6964.

Huang S, Hendriks W, Althage A, Hemmi S, Bluethmann H, Kamijo R, Vilcek J, Zinkernagel RM, Aguet M (1993) Immune response in mice that lack the interferon-gamma receptor. Science 259: 1742-1745.
Hwang SY, Hertzog PJ, Holland KA, Sumarsono SH, Tymms MJ, Hamilton JA, Whitty G, Bertoncello I, Kola I (1995) A null mutation in the gene encoding a type I interferon receptor component eliminates antiproliferative and antiviral responses to interferons alpha and beta and alters macrophage responses. Proc Natl Acad Sci USA 92: 11284-11288.

Igarashi K, David M, Larner AC, Finbloom DS (1993) In vitro activation of a transcription factor by gamma interferon requires a membrane-associated tyrosine kinase and is mimicked by vanadate. Mol Cell Biol 13: 3984-3989.

Isaacs A, Lindenmann J (1957) Virus interference. I. The interferon. Proc R Soc Lond B Biol Sci 147: 258-267.

Kessler DS, Veals SA, Fu XY, Levy DE (1990) Interferon-alpha regulates nuclear translocation and DNA-binding affinity of ISGF3, a multimeric transcriptional activator. Genes Dev 4: 1753-1765.

Khan KD, Shuai K, Lindwall G, Maher SE, Darnell JE Jr, Bothwell AL (1993) Induction of the $L y-6 A / E$ gene by interferon alpha/beta and gamma requires a DNA element to which a tyrosine-phosphorylated $91-\mathrm{kDa}$ protein binds. Proc Natl Acad Sci USA 90: 6806-6810.

Kimura T, Kadokawa Y, Harada H, Matsumoto M, Sato M, Kashiwazaki Y, Tarutani M, Tan RS, Takasugi T, Matsuyama T, Mak TW, Noguchi S, Taniguchi T (1996) Essential and non-redundant roles of p48 (ISGF3 gamma) and IRF-1 in both type I and type II interferon responses, as revealed by gene targeting studies. Genes Cells 1: 115-124.

Kisseleva T, Bhattacharya S, Braunstein J, Schindler CW (2002) Signaling through the JAK/STAT pathway, recent advances and future challenges. Gene 285: 1-24.

Kumatori A, Yang D, Suzuki S, Nakamura M (2002) Cooperation of STAT-1 and IRF-1 in interferon-gamma-induced transcription of the gp91(phox) gene. J Biol Chem 277: 9103-9111.

Larner AC, Jonak G, Cheng YS, Korant B, Knight E, Darnell JE Jr (1984) Transcriptional induction of two genes in human cells by beta interferon. Proc Natl Acad Sci USA 81: 6733-6737.

Le Bon A, Schiavoni G, D’Agostino G, Gresser I, Belardelli F, Tough DF (2001) Type I interferons potently enhance humoral immunity and can promote isotype switching by stimulating dendritic cells in vivo. Immunity 14 : 461-470.

Levy DE, Darnell JE Jr (2002) Stats: transcriptional control and biological impact. Nat Rev Mol Cell Biol 3: 651-662.

Levy DE, Lee CK (2002) What does Stat3 do? J Clin Invest 109: 1143-1148.

Levy DE, Kessler DS, Pine R, Darnell JE Jr (1989) Cytoplasmic activation of ISGF3, the positive regulator of interferon-alpha-stimulated transcription, reconstituted in vitro. Genes Dev 3: 1362-1371.

Levy DE, Lew DJ, Decker T, Kessler DS, Darnell JE Jr (1990) Synergistic interaction between interferon-alpha and interferon-gamma through induced synthesis of one subunit of the transcription factor ISGF3. EMBO J 9: 1105-1111.

Lew DJ, Decker T, Darnell JE Jr (1989) Alpha interferon and gamma interferon stimulate transcription of a single gene through different signal transduction pathways. Mol Cell Biol 9: 5404-5411.

Lew DJ, Decker T, Strehlow I, Darnell JE (1991) Overlapping elements in the guanylate-binding protein gene promoter mediate transcriptional induction by alpha and gamma interferons. Mol Cell Biol 11: 182-191.

Li X, Leung S, Qureshi S, Darnell JE Jr, Stark GR (1996) Formation of STAT1-STAT2 heterodimers and their 
role in the activation of IRF-1 gene transcription by interferon-alpha. J Biol Chem 271: 5790-5794.

Lu B, Ebensperger C, Dembic Z, Wang Y, Kvatyuk M, Lu T, Coffman RL, Pestka S, Rothman PB (1998) Targeted disruption of the interferon-gamma receptor 2 gene results in severe immune defects in mice. Proc Natl Acad Sci USA 95: 8233-8238.

Majumder S, Zhou LZ, Chaturvedi P, Babcock G, Aras S, Ransohoff RM (1998) p48/STAT-1alpha-containing complexes play a predominant role in induction of IFN-gamma-inducible protein, $10 \mathrm{kDa}$ (IP-10) by IFNgamma alone or in synergy with TNF-alpha. J Immunol 161: $4736-4744$.

Martinez-Moczygemba M, Gutch MJ, French DL, Reich NC (1997) Distinct STAT structure promotes interaction of STAT2 with the p48 subunit of the interferon-alphastimulated transcription factor ISGF3. J Biol Chem 272: 20070-20076.

Matsumoto M, Tanaka N, Harada H, Kimura T, Yokochi T, Kitagawa M, Schindler C, Taniguchi T (1999) Activation of the transcription factor ISGF3 by interferongamma. Biol Chem 380: 699-703.

Meraro D, Gleit-Kielmanowicz M, Hauser H, Levi BZ (2002) IFN-stimulated gene 15 is synergistically activated through interactions between the myelocyte/lymphocyte-specific transcription factors, PU.1, IFN regulatory factor-8/IFN consensus sequence binding protein, and IFN regulatory factor-4: characterization of a new subtype of IFN-stimulated response element. J Immunol 168: 6224-6231.

Meraz MA, White JM, Sheehan KC, Bach EA, Rodig SJ, Dighe AS, Kaplan DH, Riley JK, Greenlund AC, Campbell D, Carver-Moore K, DuBois RN, Clark R, Aguet M, Schreiber RD (1996) Targeted disruption of the Stat1 gene in mice reveals unexpected physiologic specificity in the JAK-STAT signaling pathway. Cell 84: 431-442.

Muller M, Laxton C, Briscoe J, Schindler C, Improta T, Darnell JE Jr, Stark GR, Kerr IM (1993) Complementation of a mutant cell line: central role of the $91 \mathrm{kDa}$ polypeptide of ISGF3 in the interferon-alpha and gamma signal transduction pathways. EMBO J 12: 4221-4228.

Nakaya T, Sato M, Hata N, Asagiri M, Suemori H, Noguchi S, Tanaka N, Taniguchi T (2001) Gene induction pathways mediated by distinct IRFs during viral infection. Biochem Biophys Res Commun 283: 1150-1156.

Novick D, Cohen B, Rubinstein M (1994) The human interferon alpha/beta receptor: characterization and molecular cloning. Cell 77: 391-400.

Ohmori Y, Hamilton TA (1993) Cooperative interaction between interferon (IFN) stimulus response element and kappa B sequence motifs controls IFN gamma- and lipopolysaccharide-stimulated transcription from the murine IP-10 promoter. J Biol Chem 268: 6677-6688.

Ousman SS, Wang J, Campbell IL (2005) Differential regulation of interferon regulatory factor (IRF)-7 and IRF-9 gene expression in the central nervous system during viral infection. J Virol 79: 7514-7527.

Park C, Li S, Cha E, Schindler C (2000) Immune response in Stat2 knockout mice. Immunity 13: 795-804.

Pearse RN, Feinman R, Ravetch JV (1991) Characterization of the promoter of the human gene encoding the high-affinity IgG receptor: transcriptional induction by gamma-interferon is mediated through common DNA response elements. Proc Natl Acad Sci USA 88: 1130511309.

Pearse RN, Feinman R, Shuai K, Darnell JE Jr, Ravetch JV (1993) Interferon gamma-induced transcription of the high-affinity $F_{C}$ receptor for $\operatorname{IgG}$ requires assem- bly of a complex that includes the 91-kDa subunit of transcription factor ISGF3. Proc Natl Acad Sci USA 90: 4314-4318.

Pellegrini S, Schindler C (1993) Early events in signalling by interferons. Trends Biochem Sci 18: 338-342.

Pestka S, Krause CD, Walter MR (2004) Interferons, interferon-like cytokines, and their receptors. Immunol Rev 202: 8-32.

Peters KL, Smith HL, Stark GR, Sen GC (2002) IRF-3-dependent, NFkappa B- and JNK-independent activation of the 561 and IFN-beta genes in response to doublestranded RNA. Proc Natl Acad Sci USA 99: 6322-6327.

Platanias LC (2005) Mechanisms of type-I- and type-II-interferon-mediated signalling. Nat Rev Immunol 5: 375386.

Qing Y, Stark GR (2004) Alternative activation of STAT1 and STAT3 in response to interferon-gamma. J Biol Chem 279: 41679-41685.

Qureshi SA, Salditt-Georgieff M, Darnell JE Jr (1995) Tyrosine-phosphorylated Stat1 and Stat2 plus a $48-\mathrm{kDa}$ protein all contact DNA in forming interferon-stimulatedgene factor 3. Proc Natl Acad Sci USA 92: 3829-3833.

Ramana CV, Kumar A, Enelow R (2005) Stat1-independent induction of SOCS-3 by interferon-gamma is mediated by sustained activation of Stat 3 in mouse embryonic fibroblasts. Biochem Biophys Res Commun 327: 727-733.

Reid LE, Brasnett AH, Gilbert CS, Porter AC, Gewert DR, Stark GR, Kerr IM (1989) A single DNA response element can confer inducibility by both alpha- and gamma-interferons. Proc Natl Acad Sci USA 86: 840-844.

Sarkis PT, Ying S, Xu R, Yu XF (2006) STAT1-independent cell type-specific regulation of antiviral APOBEC3G by IFN-alpha. J Immunol 177: 4530-4540.

Schindler C, Fu XY, Improta T, Aebersold R, Darnell JE Jr (1992a) Proteins of transcription factor ISGF-3: one gene encodes the 91- and 84-kDa ISGF-3 proteins that are activated by interferon alpha. Proc Natl Acad Sci USA 89: 7836-7839.

Schindler C, Shuai K, Prezioso VR, Darnell JE Jr (1992b) Interferon-dependent tyrosine phosphorylation of a latent cytoplasmic transcription factor. Science 257: 809-813.

Sehgal PB (2003) Plasma membrane rafts and chaperones in cytokine/STAT signaling. Acta Biochim Polon 50: 583594.

Seidel HM, Milocco LH, Lamb P, Darnell JE Jr, Stein RB, Rosen J (1995) Spacing of palindromic half sites as a determinant of selective STAT (signal transducers and activators of transcription) DNA binding and transcriptional activity. Proc Natl Acad Sci USA 92: 3041-3045.

Servant MJ, Tenoever B, Lin R (2002) Overlapping and distinct mechanisms regulating IRF-3 and IRF-7 function. J Interferon Cytokine Res 22: 49-58.

Shuai K, Schindler C, Prezioso VR, Darnell JE Jr (1992) Activation of transcription by IFN-gamma: tyrosine phosphorylation of a $91-\mathrm{kD}$ DNA binding protein. Science 258: 1808-1812.

Shuai K, Stark GR, Kerr IM, Darnell JE Jr (1993) A single phosphotyrosine residue of Stat91 required for gene activation by interferon-gamma. Science 261: 1744-1746.

Stark GR, Kerr IM, Williams BR, Silverman RH, Schreiber RD (1998) How cells respond to interferons. Annu Rev Biochem 67: 227-264.

Strehlow I, Seegert D, Frick C, Bange FC, Schindler C, Bottger EC, Decker T (1993) The gene encoding IFP 53/tryptophanyl-tRNA synthetase is regulated by the gamma-interferon activation factor. J Biol Chem 268: 16590-16595.

Takaoka A, Yanai H (2006) Interferon signalling network in innate defence. Cell Microbiol 8: 907-922. 
Takaoka A, Yanai H, Kondo S, Duncan G, Negishi H, Mizutani T, Kano S, Honda K, Ohba Y, Mak TW, Taniguchi T (2005) Integral role of IRF-5 in the gene induction programme activated by Toll-like receptors. Nature 434: $243-249$.

Taniguchi T, Ogasawara K, Takaoka A, Tanaka N (2001) IRF family of transcription factors as regulators of host defense. Annu Rev Immunol 19: 623-655.

Veals SA, Schindler C, Leonard D, Fu XY, Aebersold R, Darnell JE Jr, Levy DE (1992) Subunit of an alpha-interferon-responsive transcription factor is related to interferon regulatory factor and Myb families of DNAbinding proteins. Mol Cell Biol 12: 3315-3324.

Veals SA, Santa Maria T, Levy DE (1993) Two domains of ISGF3 gamma that mediate protein-DNA and protein-protein interactions during transcription factor assembly contribute to DNA-binding specificity. Mol Cell Biol 13: 196-206.

Vinkemeier U, Cohen SL, Moarefi I, Chait BT, Kuriyan J, Darnell JE Jr (1996) DNA binding of in vitro activated Stat1 alpha, Stat1 beta and truncated Stat1: interaction between NH2-terminal domains stabilizes binding of two dimers to tandem DNA sites. Embo J 15: 56165626.

Wagner TC, Velichko S, Vogel D, Rani MR, Leung S, Ransohoff RM, Stark GR, Perez HD, Croze E (2002) Interferon signaling is dependent on specific tyrosines located within the intracellular domain of IFNAR2c. Expression of IFNAR2c tyrosine mutants in U5A cells. J Biol Chem 277: 1493-1499.

Xie $R$, van Wijnen AJ, van Der Meijden C, Luong MX, Stein JL, Stein GS (2001) The cell cycle control element of histone $\mathrm{H} 4$ gene transcription is maximally responsive to interferon regulatory factor pairs IRF-1/IRF-3 and IRF-1/IRF-7. J Biol Chem 276: 18624-18632.

Xiong $\mathrm{H}$, Zhu C, Li H, Chen F, Mayer L, Ozato K, Unkeless JC, Plevy SE (2003) Complex formation of the interferon (IFN) consensus sequence-binding protein with IRF-1 is essential for murine macrophage IFNgamma-induced iNOS gene expression. J Biol Chem 278: 2271-2277.

Xu X, Sun YL, Hoey T (1996) Cooperative DNA binding and sequence-selective recognition conferred by the STAT amino-terminal domain. Science 273: 794-797.

Yang H, Lin CH, Ma G, Baffi MO, Wathelet MG (2003) Interferon regulatory factor-7 synergizes with other transcription factors through multiple interactions with p300/CBP coactivators. J Biol Chem 278: 15495-15504.

Zimmermann A, Trilling M, Wagner M, Wilborn M, Bubic I, Jonjic S, Koszinowski U, Hengel H (2005) A cytomegaloviral protein reveals a dual role for STAT2 in IFN\{gamma\} signaling and antiviral responses. J Exp Med 201: 1543-1553. 